\title{
Analysis of a taurine-dependent promoter in Sinorhizobium meliloti that offers tight modulation of gene expression
}

Mina Mostafavi, Jainee Christa Lewis, Tanisha Saini, Julian Albert Bustamante, Ivan Thomas Gao, Tuyet Thi Tran, Sean Nicholas King, Zhenzhong Huang and Joseph C Chen ${ }^{*}$

\begin{abstract}
Background: Genetic models have been developed in divergent branches of the class Alphaproteobacteria to help answer a wide spectrum of questions regarding bacterial physiology. For example, Sinorhizobium meliloti serves as a useful representative for investigating rhizobia-plant symbiosis and nitrogen fixation, Caulobacter crescentus for studying cell cycle regulation and organelle biogenesis, and Zymomonas mobilis for assessing the potentials of metabolic engineering and biofuel production. A tightly regulated promoter that enables titratable expression of a cloned gene in these different models is highly desirable, as it can facilitate observation of phenotypes that would otherwise be obfuscated by leaky expression.

Results: We compared the functionality of four promoter regions in $S$. meliloti $\left(P_{\text {araA }}, P_{\text {tauA }}, P_{\text {rhar, }}\right.$, and $\left.P_{\text {melA }}\right)$ by constructing strains carrying fusions to the uidA reporter in their genomes and measuring beta-glucuronidase activities when they were induced by arabinose, taurine, rhamnose, or melibiose. PtauA was chosen for further study because it, and, to a lesser extent, $P_{\text {melA }}$, exhibited characteristics suitable for efficient modulation of gene expression. The levels of expression from $\mathrm{P}_{\text {tau }}$ depended on the concentrations of taurine, in both complex and defined media, in S. meliloti as well as C. crescentus and Z. mobilis. Moreover, our analysis indicated that TauR, TauC, and TauY are each necessary for taurine catabolism and substantiated their designated roles as a transcriptional activator, the permease component of an $A B C$ transporter, and a major subunit of the taurine dehydrogenase, respectively. Finally, we demonstrated that $P_{\text {tauA }}$ can be used to deplete essential cellular factors in S. meliloti, such as the PleC histidine kinase and TatB, a component of the twin-arginine transport machinery.
\end{abstract}

Conclusions: The $P_{\text {tauA }}$ promoter of $S$. meliloti can control gene expression with a relatively inexpensive and permeable inducer, taurine, in diverse alpha-proteobacteria. Regulated expression of the same gene in different hosts can be achieved by placing both tauR and $P_{\text {tauA }}$ on appropriate vectors, thus facilitating inspection of conservation of gene function across species.

Keywords: Alphaproteobacteria, Rhizobia, Sphingomonadaceae, Transcriptional regulator, Beta-glucuronidase, mCherry, Taurine metabolism, Essential genes, Twin arginine translocation

\footnotetext{
* Correspondence: chenj@sfsu.edu

Department of Biology, San Francisco State University, San Francisco, CA
} 94132, USA 


\section{Background}

The class Alphaproteobacteria encompasses a multitude of noteworthy taxa with diverse physiologies. Members of the group range from human and livestock pathogens, such as Rickettsia and Brucella, to rhizobial species, such as Sinorhizobium meliloti and Agrobacterium tumefaciens (also known as Ensifer meliloti and Rhizobium radiobacter, respectively), that benefit or damage agricultural crops [1]. The possible progenitor of present-day mitochondria, and several highly abundant marine groups, including Roseobacter, SAR116, and SAR11, also belong to this class [2]. In-depth molecular studies of various representatives have led to significant insights regarding cell cycle progression [3], organelle biogenesis [4], metabolic pathways [5], microbe-host interactions [6,7], and potential for biofuel production [8].

The availability of genetic tools in readily culturable bacteria facilitates the investigation of their physiologies. In particular, an inducible promoter that allows tight titration of gene expression enables functional analysis of cellular factors that are toxic at low levels or essential for viability. For example, investigators working with Escherichia coli, a gamma-proteobacterium, possess an array of such tools at their disposal: some commonly used ones are the arabinose-inducible $\mathrm{P}_{\mathrm{BAD}}$ promoter $[9,10]$, the rhamnose-inducible $\mathrm{P}_{\text {rhaB }}$ promoter $[11]$, and various derivatives of the original $l a c$ and tet promoters $[12,13]$. Within the alpha-proteobacteria group, Caulobacter crescentus is perhaps one of the representative members most amenable to genetic manipulation, with two well characterized, regulatable promoters, inducible by xylose or vanillate [14-16]. Identification of these control elements has helped $C$. crescentus emerge as a prominent model for study of bacterial cell biology [17].

In contrast, the agriculturally important alphaproteobacterium S. meliloti, which forms mutualistic symbiosis with legume plants, lacks a selection of such fully developed induction systems. Following reciprocal exchange of chemical signals between a suitable plant host and the endosymbiont, S. meliloti infects and colonizes nodules that develop along the plant root; the bacteria enter membrane-bound compartments within cortical cells and differentiate into bacteroids, capable of converting atmospheric dinitrogen to ammonia $[6,18]$. The ability of $S$. meliloti to fix nitrogen for its hosts, especially alfalfa, improves crop yield, reduces expensive reliance on synthetic fertilizers, and enriches soil fertility in an ecologically sound manner $[19,20]$. Better tools for manipulating the bacterium would facilitate investigation of this model rhizobial-plant symbiosis. Our goal is to identify expression systems that can be modulated and efficiently shut off, thus permitting characterization of phenotypes that would otherwise be obscured by leaky expression. We are particularly interested in a system that is functional and easily transferrable among different alpha-proteobacteria. Derivatives of the E. coli lac promoter, inducible by isopropyl-beta-D-thiogalactopyranoside (IPTG), appear to serve this purpose $[21,22]$. Nevertheless, additional candidates that would enlarge the repertoire of genetic tools deserve further examination.

We chose to compare four potential promoter regions$\mathrm{P}_{\text {araA }}, \mathrm{P}_{\text {tauA }}, \mathrm{P}_{\text {rhaR }}$, and $\mathrm{P}_{\text {melA }}$-each with varying degrees of prior characterization. We selected these candidates because (1) their respective inducers are relatively affordable; (2) previous studies suggested potentials for modulating gene expression by at least one order of magnitude; and (3) genomic integrations of transcriptional fusions to the promoters can be achieved easily without disrupting genes involved in the metabolic pathways under investigation. The $\mathrm{P}_{\text {araA }}$ promoter region is located on the $\mathrm{pSymB}$ megaplasmid, upstream of the araABCDEF operon (Figure 1A), which was shown to be required for arabinose catabolism and inducible by arabinose more than 100-fold in defined medium [23]. However, expression may be subject to a certain degree of catabolite repression and inducer exclusion $[23,24] . \mathrm{P}_{\text {tauA }}, \mathrm{P}_{\text {rhaR }}$, and $\mathrm{P}_{\text {melA }}$ expression were tested in a large-scale screen for induction profiles of solute transporters and found to increase at least 100-, 6-, and 60 -fold when cells were exposed to taurine (2-aminoethanesulfonate), rhamnose, or melibiose, respectively [25]. Located on pSymB and upstream of genes thought to be involved in taurine assimilation (Figure 1B) [26,27], the $\mathrm{P}_{\text {tauA }}$ promoter region has allowed controlled expression of reporter genes in rhizobial and Rhodobacter species [28] and of the site-specific recombinase Cre in S. meliloti [29]. The $P_{\text {rhaR }}$ promoter region is located upstream of rhaR, which encodes a transcriptional regulator, and between chromosomal genes involved in rhamnose metabolism (Figure 1C) [30]. The $\mathrm{P}_{\text {mela }}$ promoter is located between agpT and melA on the pSymB megaplasmid (Figure 1D); melA and downstream genes are required for assimilation of alpha-galactosides, such as raffinose and melibiose, while AgpT is an AraC-like transcriptional activator, required for induction of the $\mathrm{P}_{\text {melA }}$ promoter $[31,32] . \mathrm{P}_{\text {mela }}$ has been used successfully in physiological studies of S. meliloti [33] and as a biosensor for environmental galactosides [34], but catabolite repression and inducer exclusion by succinate and other preferred compounds can also affect its induction [35,36].

We used transcriptional fusions to the genomic loci of these four promoters to assess their induction profiles in both complex and defined media. Our results suggested that $\mathrm{P}_{\text {tauA }}$ and $\mathrm{P}_{\text {melA }}$ offered both tighter regulation and wider ranges of expression compared to the other promoters. Further characterization of the $\mathrm{P}_{\text {tauA }}$ promoter indicated that the surrounding tau genes are required for taurine metabolism and affect expression from the promoter. We demonstrate the utility of the promoter 


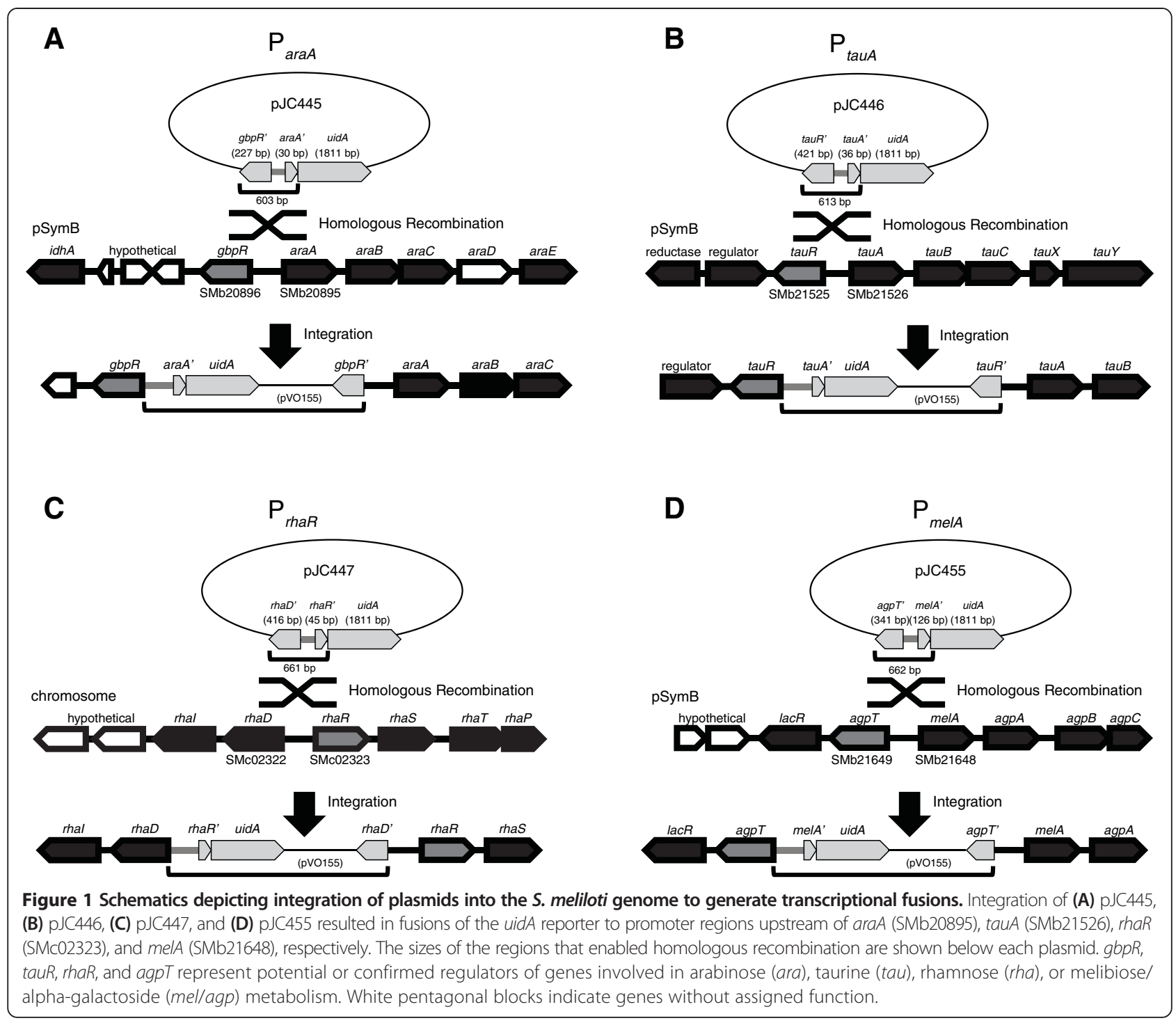

by showing that $\mathrm{P}_{\text {tauA }}$ allows modulated expression of reporter genes in two other model alpha-proteobacteria, C. crescentus and Zymomonas mobilis. Moreover, we verified that $\mathrm{P}_{\text {tauA }}$ enables tight shut-off and depletion of essential genes in S. meliloti. Thus, this study establishes the feasibility of using $\mathrm{P}_{\text {tauA }}$ as a regulatory switch in diverse alpha-proteobacteria.

\section{Results and discussion}

\section{Comparison of promoter regions in complex and defined} media

To identify a promoter region that allows controlled expression of desired genes, we compared the levels of inducible expression from four different potential promoters: $\mathrm{P}_{\text {araA }}, \mathrm{P}_{\text {tauA }}, \mathrm{P}_{\text {rhaR }}$, and $\mathrm{P}_{\text {melA }}$. These regions were chosen according to the criteria described above after reviewing previously published studies for candidates. Each promoter region was transcriptionally fused to the uidA gene [encoding the beta-glucuronidase (GUS) reporter enzyme] on a suicide plasmid, which was subsequently integrated into the $S$. meliloti genome via homologous recombination (Figure 1). We designed the constructs to minimize disruption of the target genomic regions, such that the surrounding genes and their regulation remained intact, by integrating between divergently transcribed genes. Strains carrying the reporter constructs were grown in complex (PYE, LB) or defined (M9, M9 + CAA) media for three hours to mid-log phase, with or without appropriate inducers: arabinose for $\mathrm{P}_{\text {araA } A}$, taurine for $\mathrm{P}_{\text {tauA }}$, rhamnose for $\mathrm{P}_{\text {rhaR }}$, and melibiose for $\mathrm{P}_{\text {melA }}$. For comparison in M9 minimal medium, strains were first grown in M9 supplemented with glucose (M9G), washed with M9, and then grown for three hours in M9G or M9 plus inducer as the sole carbon source. Samples were subsequently harvested for measurement of GUS activities. 
All strains exhibited higher levels of reporter gene expression in the presence of their respective inducers (Figure 2). For the $\mathrm{P}_{\text {araA }}$ promoter region, the maximal change occurred in M9 minimal medium, with a 10-fold increase in expression. Much larger changes in expression were reported in a previous study, possibly for a couple of reasons: (1) the induction time was longer; and (2) the reporter gene was inserted into araF, which is involved in arabinose catabolism [23]. Compared to other promoters, $\mathrm{P}_{\text {araA }}$ showed the highest level of induced expression in all rich and defined media tested: PYE, LB, M9, and M9 plus casamino acids (M9 + CAA). However, $\mathrm{P}_{\text {araA }}$ also showed relatively high levels of basal expression in the absence of arabinose. Basal expression was lowest in M9G (12 Miller units; Figure 2C), but it was still significantly higher than the basal expression of other promoters. Thus, while the $\mathrm{P}_{\text {araA }}$ promoter region is not suitable for tight regulation, it may serve as a useful tool for overexpression of desired genes.

The $\mathrm{P}_{\text {rhaR }}$ promoter demonstrated obvious elevation in expression when induced with rhamnose, increasing 10-fold (from 1.1 to 11 Miller units) in PYE complex medium and 38-fold (from 0.4 to 15.2 Miller units) in M9 minimal medium. However, $\mathrm{P}_{\text {rhaR }}$ also showed the lowest levels of expression, whether induced or uninduced, when compared to other promoters under similar conditions. We only measured expression from $\mathrm{P}_{\text {rhaR }}$ in PYE and M9 and did not test it in LB or M9 + CAA because other promoter regions all exhibited lower expression in LB compared to PYE and in M9 + CAA compared
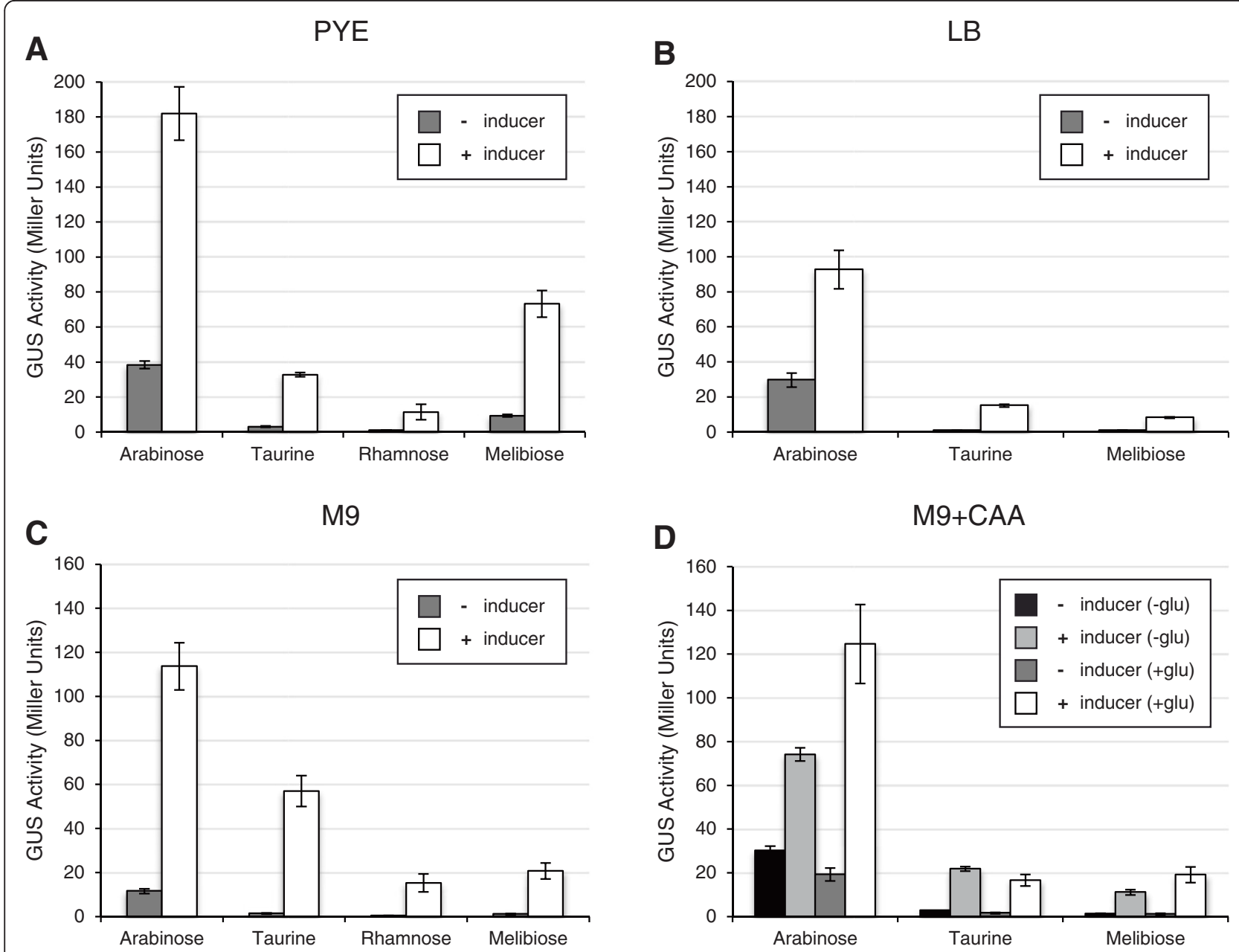

Figure 2 Comparison of promoter strengths in different culture media. Strains (JOE3273, JOE3275, JOE3277, and JOE3334) carrying transcriptional fusions of uidA to arabinose-, taurine-, rhamnose-, and melibiose-dependent promoter regions were grown in (A) PYE, (B) LB, (C) M9, or (D) M9 plus casamino acids (M9 + CAA) liquid media for three hours, to mid-log phase, in the presence or absence of appropriate inducers. Cultures were then harvested to measure the levels of beta-glucuronidase (GUS) expression. For M9+ CAA, strains were either first grown in M9+ CAA without glucose (-glu) and then diluted into the same medium with or without inducer; or they were first grown in M9+ CAA supplemented with $0.2 \%$ glucose (+glu) and diluted into M9+CAA supplemented with the inducer [+ inducer (+glu)] or glucose [- inducer (+glu)]. Error bars indicate the standard errors of the mean GUS activities. See Methods for further details. 
to M9. The results in PYE and M9 media had already suggested that the rhaR promoter region would not permit regulating genes that require high levels of expression.

The remaining two promoter regions, $\mathrm{P}_{\text {tauA }}$ and $\mathrm{P}_{\text {melA }}$, showed significant increases in GUS activities when induced. For $\mathrm{P}_{\text {tauA }}$, the increase ranged from 8-fold in $\mathrm{M} 9+$ CAA to 41-fold in M9, while for $\mathrm{P}_{\text {mela }}$ the increase ranged from 8-fold in PYE to 19-fold in M9. Both demonstrated low levels of basal expression and robust expression when induced. The notable exception occurred for $\mathrm{P}_{\text {mela }}$ in PYE, which exhibited higher levels of basal expression, suggesting leakiness in that particular medium (Figure 2A). Nevertheless, both $\mathrm{P}_{\text {tauA }}$ and $\mathrm{P}_{\text {melA }}$ emerged as useful candidates for modulating expression of desired genes.

In addition to melibiose (6-O- $\alpha$-D-galactopyranosyl-Dglucose), we had also tested raffinose [O- $\alpha$-D-galactopyranosyl-( $1 \rightarrow 6)$ - $\alpha$-D-glucopyranosyl $\beta$-D-fructofuranoside] as a potential inducer for the $\mathrm{P}_{\text {melA }}$ promoter region. Unlike melibiose, raffinose led to very little change in reporter gene expression during the three-hour induction period in all media tested (Figure 3A; data not shown). Because this result contrasted with previous reports of raffinose as an inducer of melA and agpA expression $[32,34]$, we examined induction of $\mathrm{P}_{\text {melA }}$ more closely in PYE. Induction occurred when the reporter strain carrying $\mathrm{P}_{\text {melA }}$-uidA was grown with raffinose or melibiose for 20 hours to stationary phase, with melibiose leading to stronger induction (Figure 3B). When the strain was grown with raffinose or melibiose for 12 hours, raffinose induced GUS expression if the culture reached stationary phase but not if the culture was maintained in log phase, whereas melibiose induced expression in either case (Figure 3C). Catabolic repression has been shown to influence induction of $\mathrm{P}_{\text {melA }}$ by raffinose $[35,37]$, but melibiose seems to bypass this regulation in PYE rich medium. Therefore, raffinose appears to act as an inducer of the $\mathrm{P}_{\text {mela }}$ promoter in complex medium only if the culture reaches stationary phase, while melibiose is a more versatile inducer.
Because $\mathrm{P}_{\text {tauA }}$ exhibited low levels of basal activity and a potentially more dynamic range of expression compared to other promoter regions, we characterized it further. The reporter strain carrying the genomic $\mathrm{P}_{\text {tauA-uidA fu- }}$ sion was used to monitor expression over a range of taurine concentrations, following a three-hour induction period, in both PYE (Figure 4A) and M9G (Figure 4B). The levels of expression exhibited clear dosage-dependent responses in both media. In PYE, the promoter approached maximal expression at 90 to $100 \mathrm{mM}$ taurine. (We did not use concentrations above $100 \mathrm{mM}$ because adding higher levels of taurine to the medium became impractical, as its aqueous solubility is $500 \mathrm{mM}$.) Expression increased from 1.5 to 175 Miller units, a 117-fold change. In M9G medium, expression became saturated by $5 \mathrm{mM}$ taurine. The range of expression was smaller, from an average of 1.0 to 52 Miller units, a 52-fold change. These results indicated that the $\mathrm{P}_{\text {tau } A}$ promoter exhibits a wide range of expression in both defined and complex media.

\section{Effects of tauR, tauC, and tauY on $\mathrm{P}_{\text {tauA }}$ expression}

Next, we examined the effects of representative genes in the tau region $(\operatorname{tau} R, \operatorname{tau} C$, and $\operatorname{tau} Y)$ on $\mathrm{P}_{\operatorname{tau} A}$ expression. tauR (SMb21525) encodes a transcriptional regulator of the GntR family, tauC (SMb21528) encodes the permease component of a probable taurine $\mathrm{ABC}$ transporter, and tauY (SMb21529) encodes the large subunit of the putative taurine dehydrogenase [26,38]. Genetic analyses suggested that orthologs of the TauABC transporter in E. coli and Rhodobacter capsulatus participate in taurine utilization [39-41]. Also, previous studies indicated that the TauR ortholog in R. capsulatus (49\% identity, $62 \%$ similarity, $0 \%$ gap [42]) activates expression of genes necessary for taurine dissimilation [43], and S. meliloti $\mathrm{P}_{\text {tauA }}$ requires its cognate TauR for expression in Rhizobium leguminosarum [28]. We expected similar behaviors in S. meliloti.

We first constructed strains with individual in-frame deletions of tauR, tauC, or tauY and tested their ability

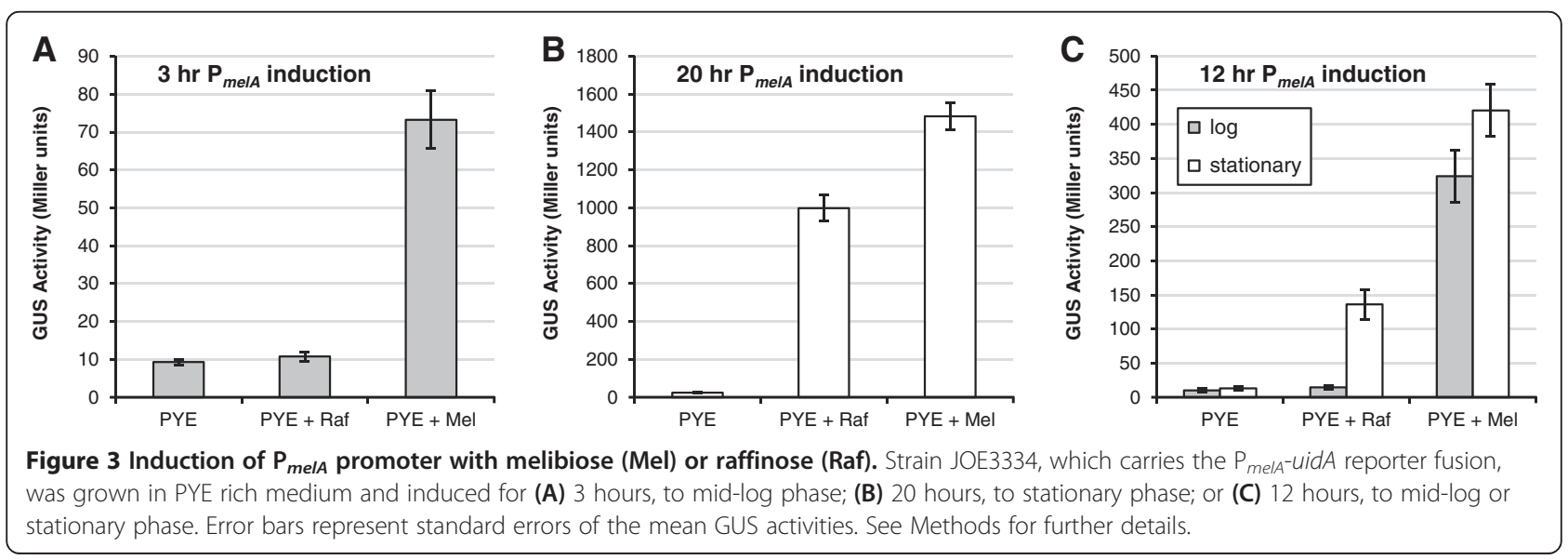



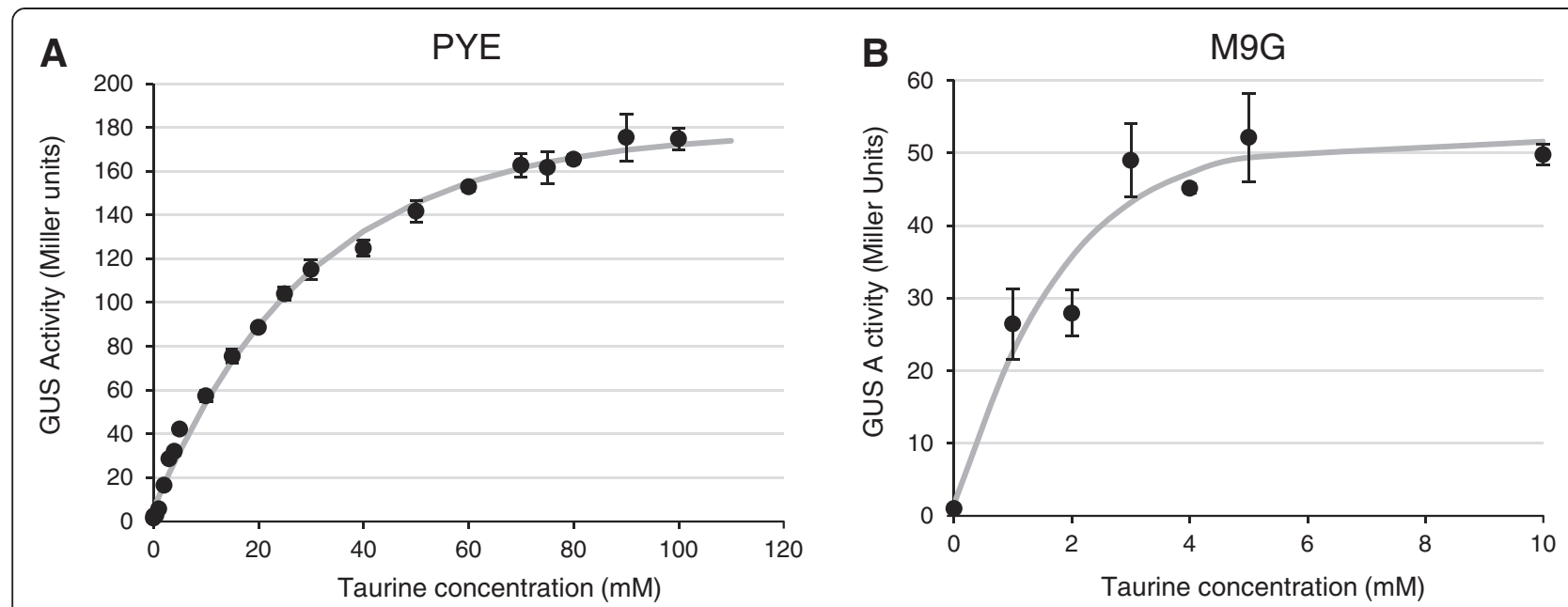

Figure 4 Dose-dependent expression of the genomic $P_{\text {tauA }}$-uidA reporter fusion. Strain JOE3275 was grown for 3 hours, to mid-log phase, in (A) PYE rich medium or (B) M9 plus $0.2 \%$ glucose (M9G) defined medium containing increasing concentrations of taurine and assayed for beta-glucuronidase (GUS) activity. (In contrast to the experiment described in Figure 2C, in which M9 contained taurine as the sole carbon source during induction, the M9 media in this experiment contained both glucose and taurine during induction.) Error bars indicate the standard errors of the mean GUS activities.

to utilize taurine as the sole carbon and energy source (Figure 5A). The Rm1021 wild-type strain formed visible colonies on M9 minimal medium supplemented with taurine after five to seven days of incubation at $30^{\circ} \mathrm{C}$, whereas all three tau mutants failed to exhibit detectable growth. Thus, $\operatorname{tau} R, \tan C$, and $\operatorname{tau} Y$ are each required for taurine dissimilation in S. meliloti. Growth was restored when each mutant was complemented with the appropriate gene on a plasmid, suggesting that the individual deletions did not deter expression of downstream genes; i.e., they were not polar mutations.

To assess the effects of the tau deletions, we used two

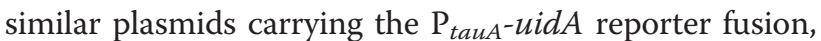
one with tauR also on the plasmid (pJC479), and the other without (pJC478). Wild-type and mutant strains transformed with the plasmids were grown in PYE in the presence or absence of taurine for three hours and then harvested to measure gene expression (Figure 5B). Except for the $\Delta \operatorname{tauR}$ mutant, all strains showed similar patterns of expression with both reporter plasmids: low basal activities in the absence of taurine and high levels of expression when induced. The $\Delta$ tauR mutant exhibited induction when $\operatorname{tau} R$ was present on the reporter plasmid but no induction when tauR was absent, confirming that TauR is the transcriptional activator for the $\mathrm{P}_{\text {tauA }}$ promoter, as previously shown [28]. Behavior of the $\triangle \operatorname{tau} C$ mutant was indistinguishable from that of the wild type, suggesting that the ABC transporter is not required for taurine to enter the cell in complex medium. Finally, whether induced or uninduced, the $\Delta \operatorname{tau} Y \mathrm{mu}-$ tant displayed the highest levels of reporter expression compared to other strains grown under similar conditions.
These results are consistent with an increased accumulation of taurine, and thus enhanced expression, in the $\Delta t a u Y$ mutant due to its inability to degrade the sulfonate compound. Higher basal expression may be attributed to low levels of taurine in the PYE complex medium itself.

Somewhat unexpectedly, deletion of $\operatorname{tau} C$, which encodes a component of the putative taurine transporter, did not affect $\mathrm{P}_{\text {tauA }}$ expression in PYE medium; because tauC is required for taurine utilization (Figure $5 \mathrm{~A}$ ), we decided to assess the effects of the tau mutations over a range of inducer concentrations in both complex and defined media. To facilitate measurement of promoter activity, we generated a plasmid bearing tauR as well as a $\mathrm{P}_{\text {tauA }}-m$ Cherry reporter fusion. Wild-type and deletion strains carrying the plasmid were grown for 20 hours with different concentrations of taurine in PYE or M9G prior to measurement of mCherry fluorescence. For all strains in PYE rich medium (Figure 5C), an increase in fluorescence directly correlated with an increase in taurine concentration. As expected, since the tauR mutation is complemented by a copy of tauR on the plasmid, the wild-type Rm1021 and $\Delta t a u R$ strains behaved similarly. Moreover, in agreement with the GUS assay results (Figure $5 \mathrm{~B}$ ), the $\Delta \operatorname{tau} Y$ mutant exhibited much higher levels of expression compared to the other strains, reaching saturation at relatively low levels of inducer (10$20 \mathrm{mM}$ taurine). The $\Delta$ tau $C$ mutant displayed slightly lower expression of $\mathrm{P}_{\text {tauA }}$ - $m$ Cherry compared to the wild type, with the difference becoming more noticeable at higher concentrations of taurine. This subtle difference in expression suggests that while $\mathrm{TauC}$ and its associated $\mathrm{ABC}$-type transporter are not absolutely required for 


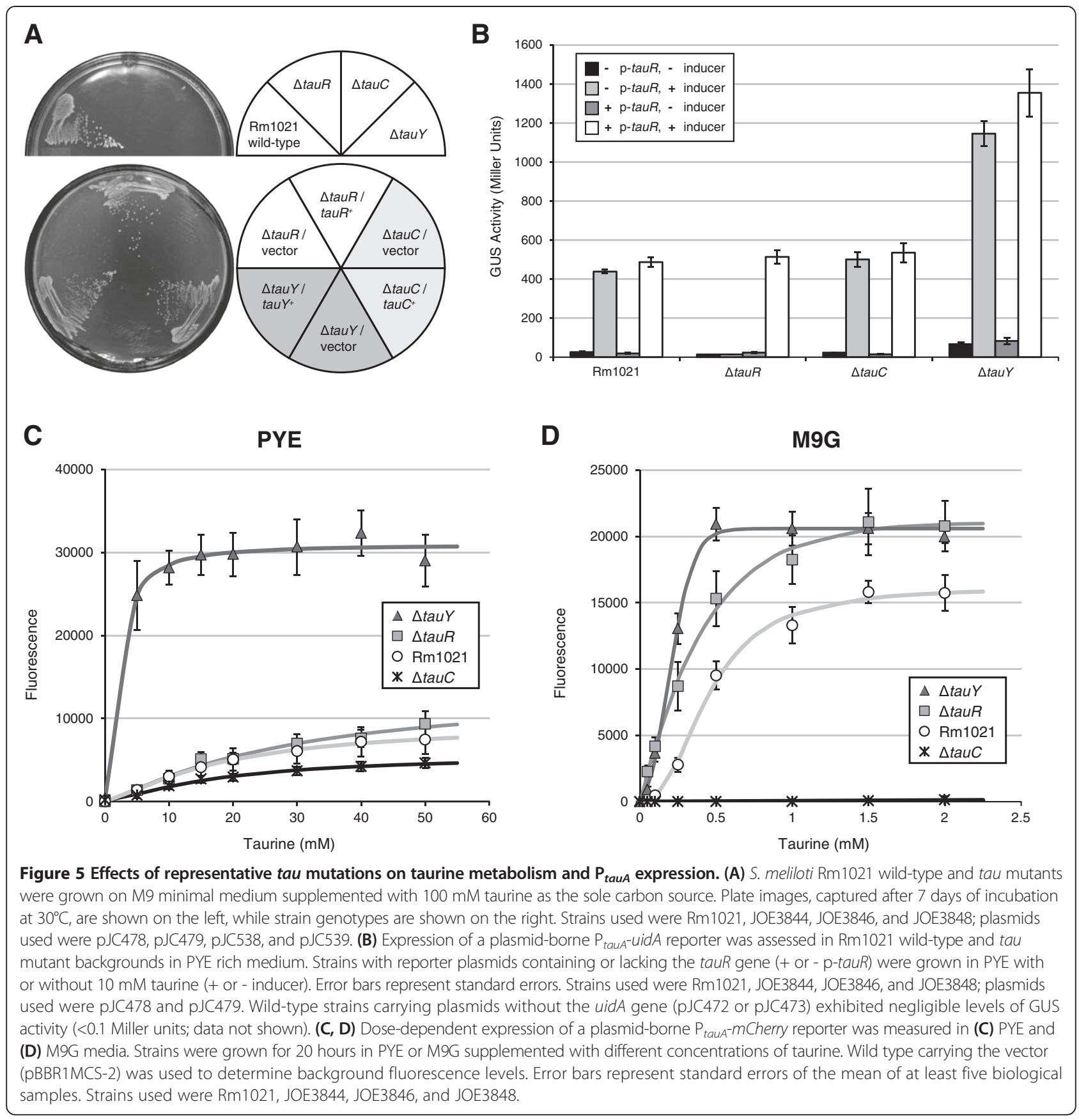

taurine import in complex medium, they may enhance the process.

In contrast, TauC is required in M9G minimal medium for import of taurine to induce $\mathrm{P}_{t a u A}$ expression. Only basal levels of fluorescence were observed with the $\triangle$ tauC mutant, regardless of taurine concentration, compared to the wild type and other tau mutants, where fluorescence correlated with increasing taurine concentration (Figure 5D). Similar to results obtained with the GUS reporter (Figure 4B), wild-type Rm1021 required much lower levels of taurine to achieve full induction in M9G compared to PYE. The $\Delta \operatorname{tau} Y$ mutant again exhibited the highest levels of expression. Intriguingly, in M9G medium the $\triangle t a u R$ mutant showed consistently higher expression relative to wild-type Rm1021 and reached levels similar to that of the $\Delta \operatorname{tau} Y$ mutant at higher taurine concentrations. We do not have a clear explanation for this observation. The Rm1021 strain actually carries two copies of tauR (one genomic, one plasmidborne) and should activate expression more readily than the $\Delta \operatorname{tau} R$ mutant, which only has one copy of the transcriptional regulator gene on the plasmid. One possibility is 
that genomic deletion of tauR influences expression of surrounding genes, such as reducing the levels of taurine dehydrogenase, and thus affects expression from the reporter plasmid.

Taken together, our results indicate that tauR encodes a transcriptional activator necessary for expression from the $\mathrm{P}_{\text {tauA }}$ promoter. TauY is involved in the degradation of taurine, most likely by forming part of the taurine dehydrogenase. The $\mathrm{ABC}$ transporter that contains TauC is required to import taurine in minimal, but not complex, medium. We speculate that the $\mathrm{ABC}$ transporter encoded by SMc02829-2832 serves as an alternative taurine uptake pathway in complex medium, because SMc02832 expression is induced by taurine, valine, isoleucine, and leucine [25].

\section{Taurine-dependent expression in C. crescentus and $Z$. mobilis}

To explore the usefulness of the $\mathrm{P}_{\text {tauA }}$ promoter in other alpha-proteobacteria, we investigated its dependence on taurine for expression in C. crescentus, a model system for studying bacterial cell cycle progression and organelle biogenesis [17]. Wild-type NA1000 carrying reporter plasmids with the $\mathrm{P}_{\text {tauA }}$-uidA fusion were harvested for GUS assays after two hours of growth in PYE medium with or without taurine. When the reporter plasmid also contained tauR (pJC479), GUS activity was high in the presence of taurine and low in its absence, indicating induction (Figure 6A, +TauR). When the reporter plasmid lacked tauR (pJC478), GUS activities remained low regardless of taurine concentration (Figure 6A, -TauR). These results confirmed that TauR is necessary to activate expression from the $\mathrm{P}_{\text {tauA }}$ promoter. Furthermore, C. crescentus does not have a functional homolog to substitute for $S$. meliloti TauR.

The same $\mathrm{P}_{\text {tauA }}$-uidA reporter strain (with tauR) was used to determine the possible range of expression in PYE medium (Figure 6B). GUS activity increased with taurine concentration and reached maximum at approximately $10 \mathrm{mM}$ taurine. Thus, much lower levels of the inducer were needed to saturate the $\mathrm{P}_{\text {tauA }}$ expression system in C. crescentus relative to S. meliloti. Expression varied approximately 19 -fold, from 150 to 2800 Miller units. Similar results were obtained using a reporter plasmid carrying tauR-P $\mathrm{P}_{\text {tau }}$ - $m$ Cherry: fluorescence levels increased with taurine concentration and approached maximum at $10 \mathrm{mM}$ taurine in PYE (Figure 6C) and $0.15 \mathrm{mM}$ taurine in $\mathrm{M} 2 \mathrm{G}$ minimal medium (Figure 6D). Therefore, the $\mathrm{P}_{\text {tauA }}$ promoter should be useful for modulating gene expression in C. crescentus.

We also examined $\mathrm{P}_{\text {tauA }}$ expression in a more distantly related alpha-proteobacterium, Z. mobilis, which possesses notable ethanol production properties of particular interest for biofuel synthesis [44]. Wild-type ZM4 carrying tauR- $\mathrm{P}_{\text {tauA }}$-mCherry on a plasmid were grown in $\mathrm{RM}$ complex or BM defined media with increasing concentrations of taurine. Fluorescence measurements yielded trends similar to those observed in S. meliloti and $C$. crescentus. First, increases in fluorescence correlated with increases in taurine concentrations in both RM (Figure 7A) and BM (Figure 7B) media. Second, the expression system approached maximal induction at lower taurine concentrations in defined medium (15 mM taurine in $\mathrm{BM}$ ) compared to complex medium (50 $\mathrm{mM}$ taurine in $\mathrm{RM})$. Thus, the $\mathrm{P}_{\text {tauA }}$ promoter can regulate gene expression in Z. mobilis. Moreover, because we observed taurinedependent expression in both C. crescentus and Z. mobilis, which belong to different phylogenetic orders (Caulobacterales and Sphingomonadales, respectively), the $\mathrm{P}_{\text {tauA }}$ promoter from $S$. meliloti (of the order Rhizobiales) may serve as a convenient genetic tool in divergent members of the class Alphaproteobacteria [1,2].

\section{Depletion of essential proteins in S. meliloti}

To demonstrate the utility of the $\mathrm{P}_{\text {tauA }}$ promoter, we constructed showcase $S$. meliloti strains that allowed depletion of cellular factors essential for viability. Essential genes were placed under the control of the $\mathrm{P}_{\text {tauA }}$ promoter, which enabled expression in the presence of taurine and shut off expression in its absence. The first example we chose was ple $C$, encoding a conserved histidine kinase required for cell division in S. meliloti [45]. The 5 ' portion of pleC was transcriptionally fused to $\mathrm{P}_{\text {tauA }}$ on a suicide plasmid, which was subsequently integrated into the native pleC locus via homologous recombination, such that the only intact copy of pleC is regulated by $\mathrm{P}_{\text {tauA }}$ (Figure $8 \mathrm{~A}$ ). The resultant strain (JOE3601) has already been shown to require taurine for viability [45] and is included here for comparison. Another depletion strain (JOE3608), in which the only copy of pleC is under the control of $\mathrm{P}_{\text {tauA }}$ on a plasmid, also exhibited a similar dependence on taurine for growth [45].

The second example we chose was $\operatorname{tat} A B C$, three contiguous genes that encode essential components of the twin arginine transport system in S. meliloti [46]. We took an approach similar to that for pleC. Because tatA is relatively small in size, and we wanted $>500 \mathrm{bp}$ of homology for efficient recombination, both tat $A$ and the 5 portion of tatB were fused to $\mathrm{P}_{\operatorname{tau} A}$ on the suicide plasmid. The resultant depletion strain has tat $A B C$ under control of $\mathrm{P}_{\text {tauA }}$, but also an intact copy of tat $A$ under control of its native promoter (Figure $8 \mathrm{~B}$ ). Presumably TatB and TatC are depleted in this strain when expression is blocked in the absence of taurine.

The PleC and TatB depletion strains grew normally, similar to wild-type, in the presence of taurine in PYE rich medium but stopped duplicating when grown in medium lacking taurine (Figure 9). The PleC depletion 


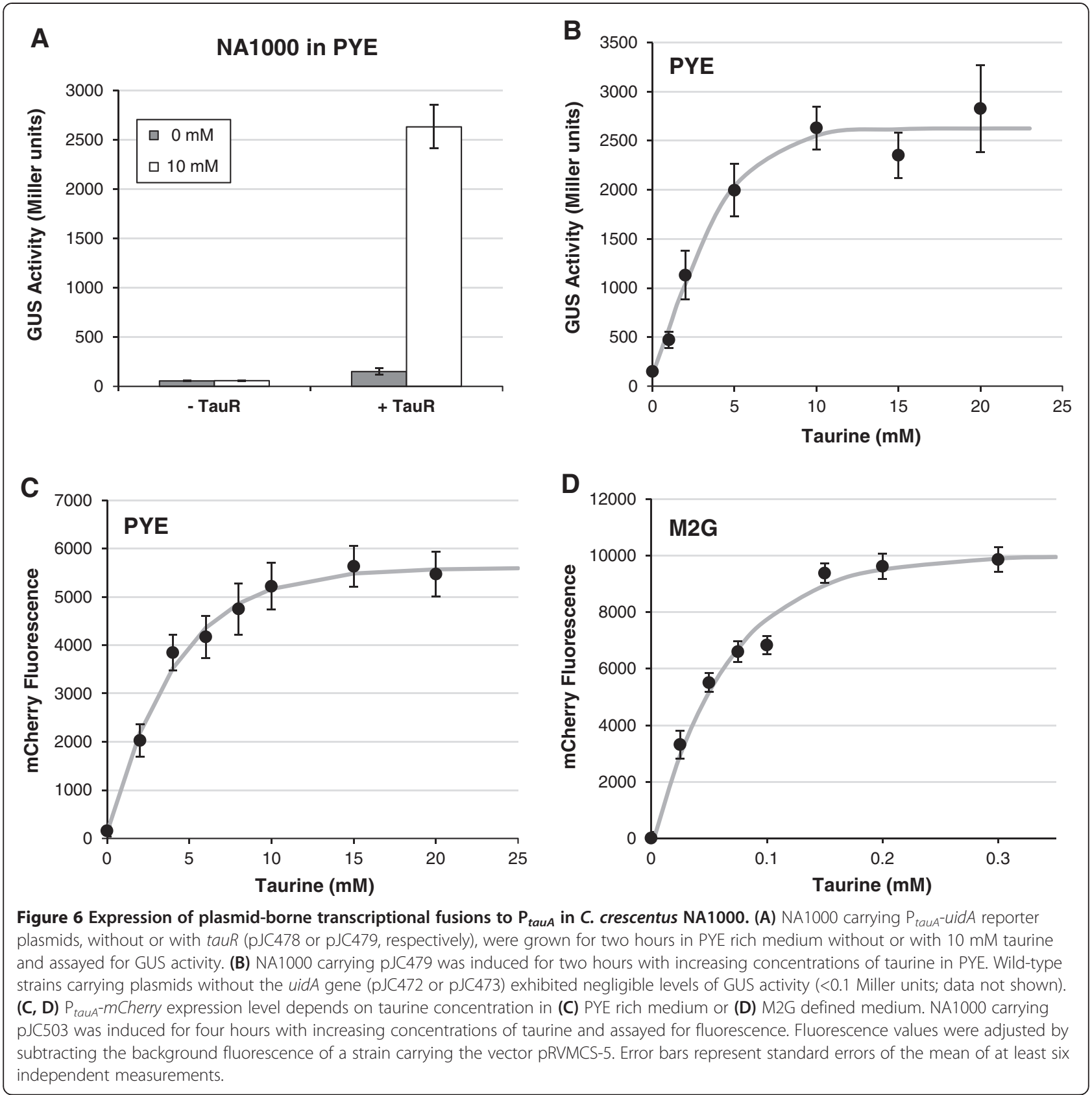

strain began slowing its growth 600 minutes (10 hours) after shifting into medium without taurine, and halted approximately 1320 minutes (22 hours) after the shift. The TatB depletion strain showed slower growth 960 minutes (16 hours) after medium shift and stopped growing also after approximately 1320 minutes. In contrast, wild-type Rm1021 displayed typical doubling regardless of taurine availability, except that the presence of taurine seemed to stimulate slightly more robust growth, most likely due to its use as a nutritional source. These results indicate that the $\mathrm{P}_{\operatorname{tau} A}$ promoter can exert tight control over the expression of essential genes and facilitate studies of physiological consequences when vital cellular components are depleted.

\section{Conclusion}

Together with previously published results [28,29], our analysis demonstrates that the $\mathrm{P}_{\text {tauA }}$ promoter of $S$. meliloti Rm1021, when paired with its cognate transcriptional activator TauR, can provide robust tuning of gene expression in diverse model organisms of the class Alphaproteobacteria, including members of Rhizobiales ( $R$. leguminosarum Rlv3841, $R$. etli CE3, and S. fredii NGR234), Rhodobacterales (R. sphaeroides WS8N), Sphingomonadales (Z. mobilis 


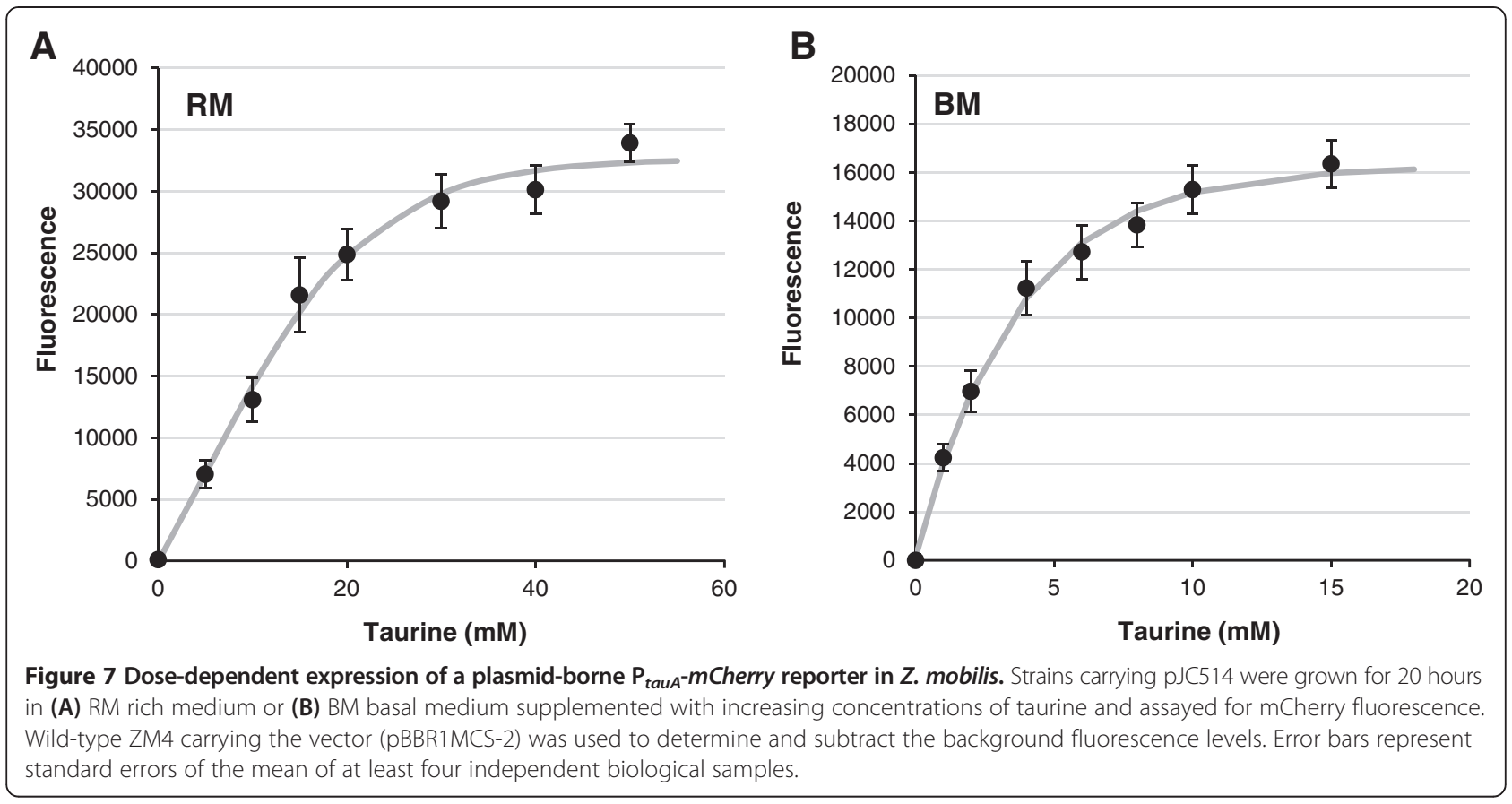

ZM4), and Caulobacterales (C. crescentus NA1000). Import of taurine does not appear to pose a challenge, despite the absence of known or obvious transporters for the inducer in many of the organisms tested. $\mathrm{P}_{\operatorname{tau} A}$ and tauR, as well as other promoter regions described above, can be readily amplified from plasmids reported here and elsewhere $[28,29]$ and cloned into other vectors that are more suitable for the end user. Therefore, this study adds to the repertoire of tools available for analyzing genetic models of Alphaproteobacteria. Because taurine has been shown to activate expression of genes other than those in the tau region, such as rpoE1 and rpoE4, in S. meliloti [47], the addition of taurine as an inducer may cause ancillary and potentially undesirable effects, particularly in untested organisms. Thus, appropriate control strains, such as one harboring an empty vector, should be included for comparison when examining the physiological consequences of inducing a gene of interest under the control of $\mathrm{P}_{\text {tauA } A}$.

In its native host, $\mathrm{P}_{\text {tauA }}$ permits depletion of essential proteins and tight regulation of potentially toxic genes, especially if combined with careful manipulation of translational efficiency; specifically, Harrison et al. [29] was able to reduce the level of expression from $\mathrm{P}_{\text {tauA }}$ by modifying sequences adjacent to the ribosome binding site such that they form RNA secondary structures. Overexpression of the gene under $\mathrm{P}_{\text {tauA }}$ control can be conducted in the $\Delta \operatorname{tau} Y$ background, in which inducer level remains high due to the inability to degrade
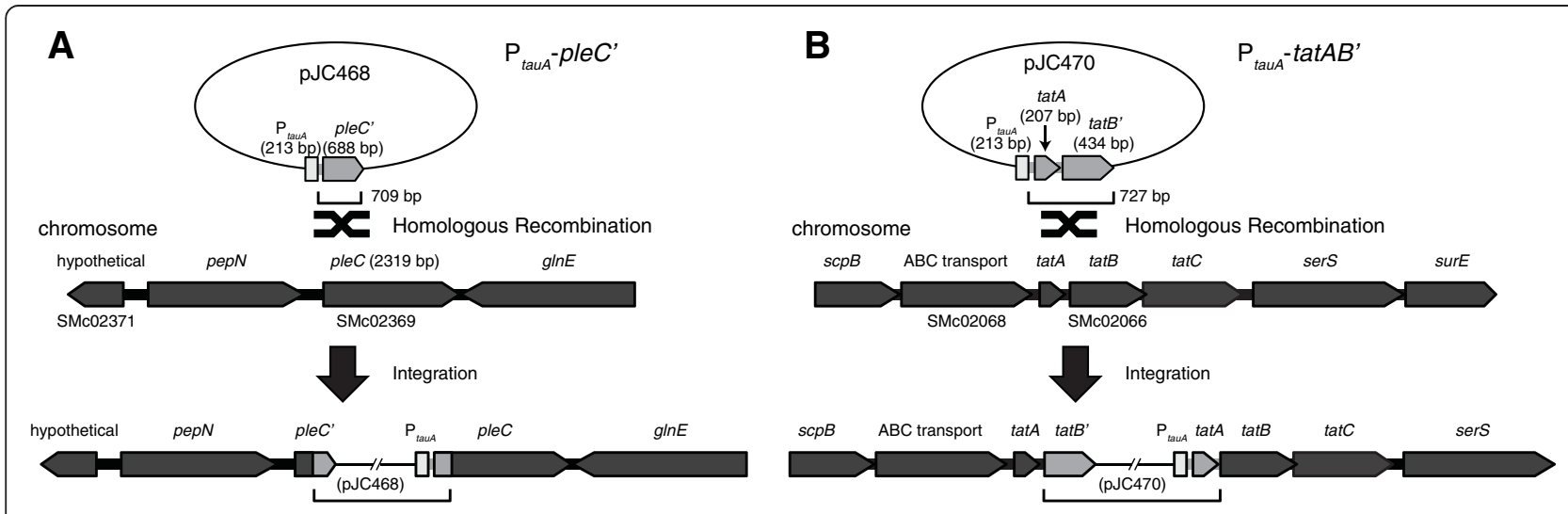

Figure 8 Schematics depicting integration of plasmids into the S. meliloti chromosome to generate depletion strains. Integration of (A) pJC468 or (B) pJC470 placed the only intact copy of pleC or tatB, respectively, under control of the $P_{\text {tauA }}$ promoter. The sizes of the regions that enabled homologous recombination are shown below each plasmid. 


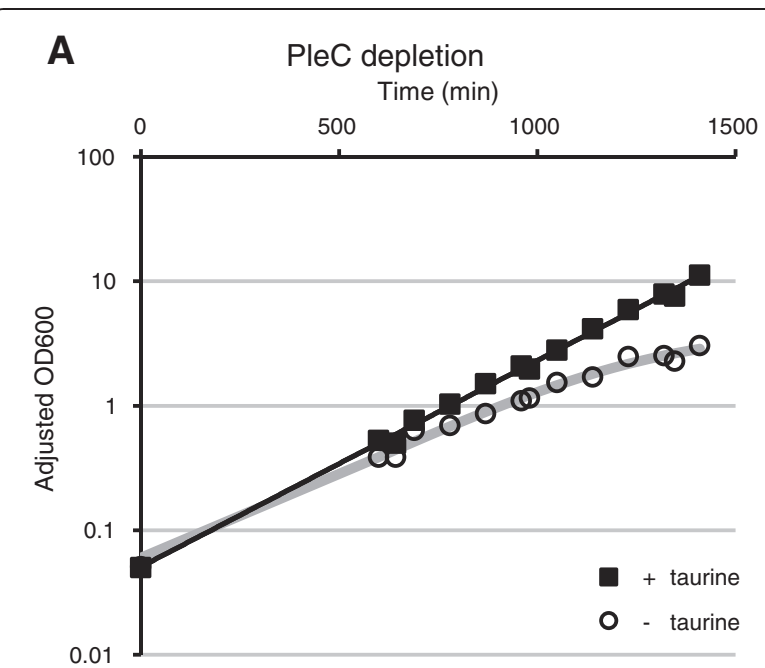

B
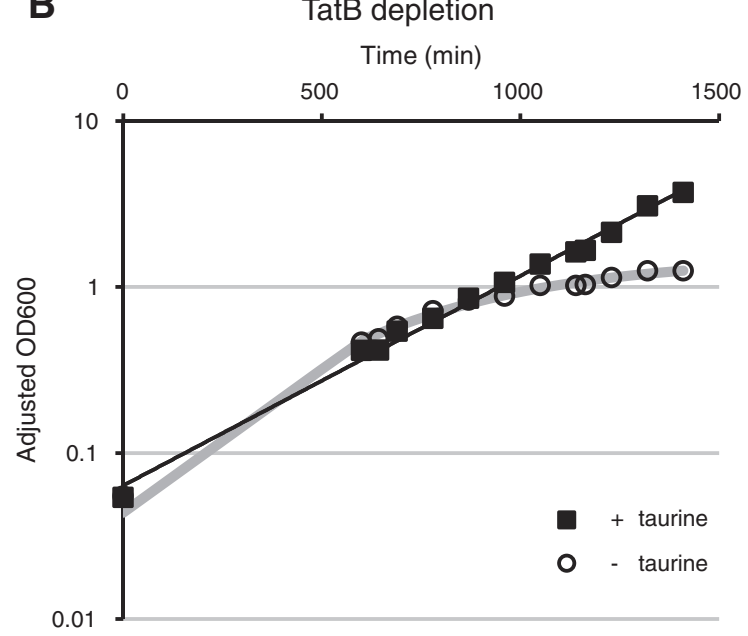

C

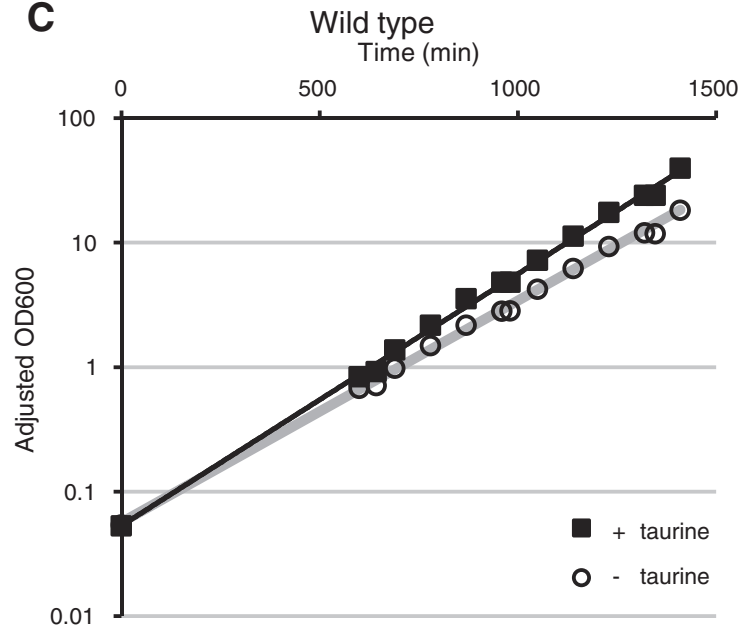

Figure 9 Representative growth curves showing depletion of PleC and TatB. (A) PleC depletion (JOE3601), (B) TatB depletion (JOE3604), and (C) wild-type Rm1021 strains were grown in PYE rich medium without or with $100 \mathrm{mM}$ taurine. Absorbance at $600 \mathrm{~nm}$ (OD600) was used to monitor the growth of cultures, and measurements were adjusted accordingly when cultures were diluted to maintain growth in log phase.

taurine. Considering the ranges of expression observed, similar levels of control in other host organisms should be achievable with appropriate adjustments, including alterations of copy number via placement in the genome or on plasmids. The possibility of using the same construct to control expression in different alpha-proteobacteria can expedite examination of gene function across species: for example, we can use the same plasmid to determine whether an essential gene from one organism can complement null mutations in its orthologs. Although $\mathrm{P}_{\text {tauA }}$ currently does not appear regulatable outside of the alpha-proteobacteria group, for instance in E. coli or Pseudomonas aeruginosa [28], further investigation and engineering may broaden the range of its functionality.

\section{Methods}

Bacterial strains, growth conditions, and genetic techniques Strains and plasmids used in this study are listed in Tables 1 and 2. S. meliloti strains were grown at $30^{\circ} \mathrm{C}$ in LB ( $1 \%$ tryptone, $0.5 \%$ yeast extract, $1 \% \mathrm{NaCl}$ ) [48], PYE ( $0.2 \%$ peptone, $0.1 \%$ yeast extract, $1 \mathrm{mM} \mathrm{MgSO}_{4} ; 0.5 \mathrm{mM}$ $\mathrm{CaCl}_{2}$ added only for liquid medium) $[49,50]$, or M9 minimal medium [51], with antibiotics when appropriate: streptomycin $\left(250 \mu \mathrm{g} \mathrm{ml}^{-1}\right)$, neomycin $\left(50\right.$ or $\left.100 \mu \mathrm{g} \mathrm{ml}^{-1}\right)$, gentamicin $\left(20 \mu \mathrm{g} \mathrm{ml}^{-1}\right)$, and oxytetracycline $(0.5$ or $1 \mu \mathrm{g} \mathrm{ml}^{-1}$ ). M9G contained $0.2 \% \mathrm{D}$-glucose as carbon source, M9+CAA contained $0.2 \%$ casamino acids, and, for counter-selection against sacB, PYE contained 3\% sucrose. $C$. crescentus NA1000 and its derivatives were grown at $30^{\circ} \mathrm{C}$ in PYE or M2G media [49], with nalidixic acid $\left(20 \mu \mathrm{g} \mathrm{ml}^{-1}\right)$ and oxytetracycline $\left(1 \mu \mathrm{g} \mathrm{ml}^{-1}\right)$ when appropriate. (M2 minimal medium was supplemented with $0.2 \%$ glucose to make M2G.) Z. mobilis ZM4 and its derivatives were grown at $30^{\circ} \mathrm{C}$ in RM or BM media [52], with nalidixic acid $\left(20 \mu \mathrm{g} \mathrm{ml}^{-1}\right)$ and kanamycin $\left(200 \mu \mathrm{g} \mathrm{ml}^{-1}\right)$ when appropriate. The original recipe for $\mathrm{BM}$ medium was modified by using yeast nitrogen base (YNB) without amino acids and ammonium sulfate (Difco) as the source of vitamins and trace elements. To make BM, we first dissolved and autoclaved $0.1 \mathrm{~g} \mathrm{~K}_{2} \mathrm{HPO}_{4}, 0.1 \mathrm{~g}$ $\left(\mathrm{NH}_{4}\right)_{2} \mathrm{SO}_{4}, 40 \mathrm{mg} \mathrm{NaCl}$, and $2 \mathrm{~g}$ glucose in $90 \mathrm{~mL}$ water; after the solution cooled, we added the following filter-sterilized solutions: $0.9 \mathrm{~mL} 10 \mathrm{mM} \mathrm{FeSO}_{4}, 1 \mathrm{~mL}$ $10 \mathrm{mM} \mathrm{Na} 2 \mathrm{MoO}_{4}$, and $10 \mathrm{~mL}$ 10X YNB (1.7 $\mathrm{g} \mathrm{YNB}$ without amino acids and ammonium sulfate dissolved in $100 \mathrm{~mL}$ water). E. coli strains were grown at $37^{\circ} \mathrm{C}$ in 
Table 1 Strains used in this study

\begin{tabular}{|c|c|c|}
\hline Strain & Relevant genetic markers, features, and/or description & Construction, source, or reference \\
\hline $\mathrm{DH} 5 \mathrm{a}$ & $\begin{array}{l}\text { Escherichia coli cloning strain: } F \text { Q } 980 \text { lacZ } \triangle \mathrm{M} 15 \Delta \text { (lacZYA-argF)U169 } \\
\text { endA1 recAl hsdR17 (rk-, mk+) deoR thi-1 supE44 gyrA96 relA1 }\end{array}$ & Invitrogen \\
\hline $\mathrm{DH} 10 \mathrm{~B}$ & $\begin{array}{l}\text { Escherichia coli cloning strain: } F \text { mcrA } \Delta \text { (mrr-hsdRMS-mcrBC) } \varphi 801 a c Z \Delta M 15 \\
\Delta \text { lacX74 endA1 recA1 deoR } \Delta(\text { ara, leu)7697 araD139 galu galk nupG rpsL }\end{array}$ & Invitrogen \\
\hline MT616 & MT607/pRK600; Escherichia coli helper strain for mobilizing RK2/RP4-derived plasmids & [53] \\
\hline NA1000 & $\begin{array}{l}\text { Caulobacter crescentus syn-1000; previously called CB15N, a synchronizable derivative } \\
\text { of wild-type CB15 }\end{array}$ & [54] \\
\hline ZM4 & Zymomonas mobilis wild-type strain, previously called CP4 & [55] \\
\hline Rm1021 & Sinorhizobium meliloti SU47 derivative, $\mathrm{Sm}^{\mathrm{R}}$ (progenitor of strains listed below) & {$[56]$} \\
\hline JOE3273 & SMb20895::pJC445 (P araA-uidA) & Mate pJC445 into Rm1021, select for $\mathrm{Nm}^{\mathrm{R}}$ \\
\hline JOE3275 & SMb21526::pJC446 (P tauA-uidA) & Mate pJC446 into Rm1021, select for $\mathrm{Nm}^{\mathrm{R}}$ \\
\hline JOE3277 & SMc02323::pJC447 (P rhar-UidA) & Mate pJC447 into Rm1021, select for $\mathrm{Nm}^{\mathrm{R}}$ \\
\hline JOE3334 & SMb21648::pJC455 (P melA-uidA) & Mate pJC455 into Rm1021, select for $\mathrm{Nm}^{\mathrm{R}}$ \\
\hline JOE3601 & SMc02369::pJC468 (P tauA-pleC) & Mate pJC468 into Rm1021, select for $\mathrm{Nm}^{\mathrm{R}}$ \\
\hline JOE3604 & SMc02066::pJC470 ( (tauA $_{\text {tat }}$-tB $)$ & Mate pJC470 into Rm1021, select for $\mathrm{Nm}^{\mathrm{R}}$ \\
\hline JOE3844 & $\Delta \operatorname{tau} R(\Delta \mathrm{SMb} 21525)$ & Allelic replacement using pJC507 \\
\hline JOE3846 & $\Delta \operatorname{tauC}(\Delta \mathrm{SMb} 21528)$ & Allelic replacement using pJC508 \\
\hline JOE3848 & $\Delta$ tauY (ASMb21529) & Allelic replacement using pJC509 \\
\hline
\end{tabular}

LB, supplemented with gentamicin (15-20 $\left.\mu \mathrm{g} \mathrm{ml}^{-1}\right)$, kanamycin $\left(30-50 \mu \mathrm{g} \mathrm{ml}^{-1}\right)$, or oxytetracycline $\left(12 \mu \mathrm{g} \mathrm{ml}^{-1}\right)$ when appropriate. All solid media contained 1.5\% agar. Stock concentrations of casamino acids and various sugars were each $20 \%(\mathrm{w} / \mathrm{v})$, while that of taurine was $0.5 \mathrm{M}$.

Mobilization of plasmids from E. coli to S. meliloti, C. crescentus, or $Z$. mobilis was accomplished by triparental mating, with the help of strain MT616, carrying pRK600 [53]; nalidixic acid or streptomycin was used to select against E. coli donor and helper strains. Electroporation of plasmid DNA into C. crescentus was achieved using cuvettes with 1-mm gaps and a Bio-Rad Gene Pulser II with the following settings: $400 \Omega, 25 \mu \mathrm{F}$, and $1.5 \mathrm{kV}$ [50]. Deletions in the $S$. meliloti genome were generated by homologous recombination and allelic replacement, using a two-step selection procedure with the vector pJQ200sk $[59,61]$. Plasmid integrations and genomic deletions were screened and confirmed by PCR. Construction of depletion strains required the presence of $100 \mathrm{mM}$ taurine in the medium while selecting for transconjugants.

\section{Molecular cloning}

Standard techniques were used for cloning and analysis of DNA, PCR, and transformation into E. coli [51,62]. Plasmids and DNA fragments were isolated using commercial kits from Qiagen. KOD polymerase (Novagen) or MangoMix (Bioline) was used for high- or low-fidelity PCR amplification, respectively, while other enzymes used to manipulate DNA came from New England BioLabs. Elim Biopharmaceuticals provided oligonucleotide synthesis and DNA sequencing services. Details of plasmid construction are described in Additional file 1. Oligonucleotide sequences are provided in Additional file 2.

\section{Beta-glucuronidase (GUS) reporter assays}

We monitored expression of the uidA reporter, under the control of various promoters, by assessing betaglucuronidase activities as previously described [63], except lysozyme was omitted and $400 \mu \mathrm{L} 1 \mathrm{M}$ sodium carbonate was added to stop each reaction. Enzymatic activity in each biological sample was measured in duplicates or triplicates, and measurements from at least three independent biological samples were averaged.

For comparison of different promoters, S. meliloti strains were grown in PYE, LB, or M9 liquid media overnight, diluted to the desired optical density, and induced for three hours, to mid-log phase, with $0.2 \%$ (13.3 $\mathrm{mM})$ L-arabinose, $0.063 \%(5 \mathrm{mM})$ taurine, $0.2 \%$ (11.0 mM) L-rhamnose monohydrate, 0.2\% (5.6 mM) D-melibiose monohydrate, or $0.2 \%(3.4 \mathrm{mM})$ D-raffinose pentahydrate. For induction in M9, strains were grown in M9 supplemented with $0.2 \%$ glucose (M9G), washed in M9 buffer without carbon source, and diluted into M9G or M9 plus inducer as the sole carbon source. For induction in M9 supplemented with $0.2 \%$ casamino acids (M9 + CAA), strains were either first grown in M9+CAA without glucose and then diluted into the same medium with or without inducer; or they were first grown in M9+CAA supplemented with $0.2 \%$ glucose, washed with M9+CAA, and diluted into M9+CAA supplemented with either glucose or the inducer. 
Table 2 Plasmids used in this study

\begin{tabular}{|c|c|c|}
\hline Plasmid & Relevant genetic markers, features, and/or description & $\begin{array}{l}\text { Construction, source, } \\
\text { or reference }\end{array}$ \\
\hline pBBR1MCS-2 & Broad-host-range vector, $\mathrm{Km}^{\mathrm{R}}$ & [57] \\
\hline pCM130 & RK2-derived broad-host-range vector with $E$. coli $r r n B$ terminator preceding polylinker, $T c^{R}$ & [58] \\
\hline pJQ200sk & Counter-selectable vector for allelic replacement, $s a c B, \mathrm{Gm}^{\mathrm{R}}$ & [59] \\
\hline pRVMCS-5 & RK2-derived broad-host-range vector with $C$. crescentus $P_{\text {van }}$ promoter, $T c^{R}$ & [14] \\
\hline pVCHYN-5 & Narrow-host-range vector with C. crescentus $P_{\text {van }}$ promoter and $m C$ herry, $T c^{R}$ & [14] \\
\hline pVO155 & pUC119-derived suicide vector with uidA cassette, $\mathrm{Nm}^{\mathrm{R}} / \mathrm{Km}^{\mathrm{R}} A \mathrm{p}^{\mathrm{R}}$ & [60] \\
\hline pJC445 & pVO155- $P_{\text {araA, }}$ for fusing uidA to sequence upstream of araA & This study \\
\hline pJC446 & pVO155- $P_{\text {tauA, }}$ for fusing uidA to sequence upstream of tauA & This study \\
\hline pJC447 & pVO155- $P_{\text {rhaR, }}$ for fusing uidA to sequence upstream of rhaR & This study \\
\hline pJC455 & pVO155- $P_{\text {melA, }}$ for fusing uidA to sequence upstream of melA & This study \\
\hline pJC468 & pVO155- $\mathrm{P}_{\text {tauA }}-$ pleC', for integrating into chromosome and placing pleC under control of $\mathrm{P}_{\text {tauA }}$ & This study \\
\hline pJC470 & pVO155- $P_{\text {tauA }}$-tat $A B^{\prime}$, for integrating into chromosome and placing tat $B$ and tat $C$ under control of $P_{\text {tauA }}$ & This study \\
\hline pJC472 & pCM130- $P_{\text {tauA }}$ & This study \\
\hline pJC473 & pCM130-tauR-P tauA & This study \\
\hline pJC474 & pRVMCS-5-derived plasmid carrying $P_{\text {tauA }}$ & This study \\
\hline pJC475 & pRVMCS-5-derived plasmid carrying tauR-P tauA & This study \\
\hline pJC478 & pCM130-P tauA-uidA & This study \\
\hline pJC479 & pCM130-tauR-P tauA-uidA & This study \\
\hline pJC503 & pRVMCS-5-derived plasmid carrying tauR-P tauA-mCherry & This study \\
\hline pJC507 & pJQ200sk- $\Delta$ tauR & This study \\
\hline pJC508 & pJQ200sk- $\Delta$ tauC & This study \\
\hline pJC509 & pJQ200sk- $\Delta$ tauY & This study \\
\hline pJC514 & pBBR1MCS-2-tauR-P tauA $_{\text {-mCherry }}$ & This study \\
\hline pJC538 & pCM130-P tauA-tauC & This study \\
\hline pJC539 & pCM130-P tauA-tauY & This study \\
\hline
\end{tabular}

For comparison of melibiose and raffinose as inducers of $\mathrm{P}_{\text {melA }}$, strain JOE3334 was grown in PYE in the presence or absence of the inducer for three hours to mid-log phase, for 20 hours to stationary phase, or for 12 hours to mid-log or stationary phase, by diluting the starter PYE cultures appropriately.

For induction with different concentrations of taurine, S. meliloti strains were grown for three hours in PYE or M9G to mid-log phase. For induction with taurine concentrations above $10 \mathrm{mM}$ in PYE, cultures were adjusted to the desired optical density by mixing appropriate volumes of the starter culture, $0.5 \mathrm{M}$ taurine, water, and double-strength PYE (2X PYE), to prevent excessive dilution of nutrients in the medium. Similar procedures were used to measure GUS activity in C. crescentus, except the strains were induced for two hours.

\section{Measurement of mCherry fluorescence}

To monitor mCherry expression in S. meliloti, we cultivated strains harboring pBBR1MCS-2 or pJC514 overnight in PYE or M9G supplemented with neomycin $\left(5 \mu \mathrm{g} \mathrm{ml}^{-1}\right)$ and then diluted the cultures in media containing different concentrations of taurine, to a final volume of $0.8 \mathrm{~mL}$ in each well of a 48 -well microtiter plate. The plates were shaken for 20 hours, and $150 \mu \mathrm{L}$ of each culture was transferred to a 96-well optic plate in duplicates for absorbance $(535 \mathrm{~nm})$ and fluorescence $(550 \mathrm{~nm}$ excitation, $610 \mathrm{~nm}$ emission) measurements with a Tecan Spectrafluor Plus reader. Expression in Z. mobilis was monitored in a similar fashion, except the strains were grown in RM or BM supplemented with kanamycin $\left(100 \mu \mathrm{g} \mathrm{ml}^{-1}\right)$. For C. crescentus, NA1000 carrying pJC503 or pRVMCS-5 was induced in PYE or M2G (M2 plus $0.2 \%$ glucose $)$ containing oxytetracycline $\left(0.5 \mu \mathrm{g} \mathrm{ml}^{-1}\right)$ and different concentrations of taurine for four hours. Absorbance readings confirmed similar levels of growth for all samples of the same species. Fluorescence readings were adjusted by subtracting the background fluorescence of strains carrying only the vector (pBBR1MCS-2 or pRVMCS-5). Average background fluorescence readings (in arbitrary units) were approximately 10000 and 21000 for S. meliloti in PYE and M9G, 23000 and 30000 
for $C$. crescentus in PYE and M2G, and 14000 and 22000 for Z. mobilis in RM and BM. Measurements of at least four biological samples, grown on separate days, were averaged following appropriate subtraction of background readings.

\section{Additional files}

Additional file 1: Plasmid construction. Construction of each plasmid is described in detail in this file.

Additional file 2: Primers used. This file contains a table of primers used in this study and their sequences.

\section{Competing interests}

The authors declare that they have no competing interests.

\section{Authors' contributions}

MM, JCL, TS, JAB, ITG, TTT, SNK, ZH, and JCC carried out experiments and performed data analysis. MM, JCL, and JCC wrote the manuscript. All authors read and approved the final manuscript.

\section{Acknowledgements}

We thank past and present members of the Chen lab for their technical assistance, Jeffrey M. Skerker for providing Z. mobilis ZM4, and Robert F. Fisher and Melanie J. Barnett for critical appraisal of the manuscript. This work was supported by the National Institute of General Medical Sciences of the National Institutes of Health (NIH) under Award Number SC3GM096943. $J C L, T S$, and $J A B$ were funded by the following programs: NIH MARC (T34-GM008574), NIH MBRS-RISE (R25-GM059298), NIH MS-PhD Bridge (R25-GM048972), and the Genentech Foundation MS Dissertation Scholarship. Additional financial support came from the College of Science and Engineering, San Francisco State University. The content is solely the responsibility of the authors and does not necessarily represent the official views of the $\mathrm{NIH}$ or other funding agencies.

Received: 27 August 2014 Accepted: 13 November 2014

Published online: 25 November 2014

\section{References}

1. Lee KB, Liu CT, Anzai Y, Kim H, Aono T, Oyaizu H: The hierarchical system of the 'Alphaproteobacteria': description of Hyphomonadaceae fam. nov. Xanthobacteraceae fam. nov. and Erythrobacteraceae fam. nov. Int I Syst Evol Microbiol 2005, 55(Pt 5):1907-1919.

2. Ferla MP, Thrash JC, Giovannoni SJ, Patrick WM: New rRNA gene-based phylogenies of the Alphaproteobacteria provide perspective on major groups, mitochondrial ancestry and phylogenetic instability. PLOS One 2013, 8(12):e83383.

3. Ardissone $\mathrm{S}$, Viollier PH: Developmental and environmental regulatory pathways in alpha-proteobacteria. Front Biosci (Landmark Ed) 2012, 17:1695-1714

4. Komeili A: Molecular mechanisms of compartmentalization and biomineralization in magnetotactic bacteria. FEMS Microbiol Rev 2012, 36(1):232-255

5. Vuilleumier $S$, Chistoserdova L, Lee MC, Bringel F, Lajus A, Zhou Y, Gourion B, Barbe V, Chang J, Cruveiller S, Dossat C, Gillett W, Gruffaz C, Haugen E, Hourcade E, Levy R, Mangenot S, Muller E, Nadalig T, Pagni M, Penny C, Peyraud R, Robinson DG, Roche D, Rouy Z, Saenampechek C, Salvignol G, Vallenet D, Wu Z, Marx CJ, et al: Methylobacterium genome sequences: a reference blueprint to investigate microbial metabolism of $\mathrm{C} 1$ compounds from natural and industrial sources. PLoS One 2009, 4(5):e5584.

6. Jones KM, Kobayashi H, Davies BW, Taga ME, Walker GC: How rhizobial symbionts invade plants: the Sinorhizobium-Medicago model. Nat Rev Microbiol 2007, 5(8):619-633.

7. Kondorosi $E$, Mergaert $P$, Kereszt A: A paradigm for endosymbiotic life: cell differentiation of Rhizobium bacteria provoked by host plant factors. Annu Rev Microbiol 2013, 67:611-628.

8. Todhanakasem T, Sangsutthiseree A, Areerat K, Young GM, Thanonkeo P. Biofilm production by Zymomonas mobilis enhances ethanol production and tolerance to toxic inhibitors from rice bran hydrolysate. N Biotechnol 2014, 31(5):451-459.

9. Guzman LM, Belin D, Carson MJ, Beckwith J: Tight regulation, modulation and high-level expression by vectors containing the arabinose $P_{B A D}$ promoter. J Bacteriol 1995, 177(14):4121-4130.

10. Morgan-Kiss RM, Wadler C, Cronan JE Jr: Long-term and homogeneous regulation of the Escherichia coli araBAD promoter by use of a lactose transporter of relaxed specificity. Proc Natl Acad Sci USA 2002, 99(11):7373-7377.

11. Sibley $\mathrm{MH}$, Raleigh EA: A versatile element for gene addition in bacterial chromosomes. Nucleic Acids Res 2012, 40(3):e19.

12. Lutz $R$, Bujard $H$ : Independent and tight regulation of transcriptional units in Escherichia coli via the LacR/O, the TetR/O and $\mathrm{AraC} / \mathrm{I}_{1}-\mathrm{I}_{2}$ regulatory elements. Nucleic Acids Res 1997, 25(6):1203-1210.

13. Brosius J, Erfle M, Storella J: Spacing of the -10 and -35 regions in the tac promoter. Effect on its in vivo activity. J Biol Chem 1985, 260(6):3539-3541.

14. Thanbichler M, Iniesta AA, Shapiro L: A comprehensive set of plasmids for vanillate- and xylose-inducible gene expression in Caulobacter crescentus. Nucleic Acids Res 2007, 35(20):e137.

15. Meisenzahl AC, Shapiro L, Jenal U: Isolation and characterization of a xylose-dependent promoter from Caulobacter crescentus. J Bacteriol 1997, 179(3):592-600.

16. Stephens C, Christen B, Watanabe K, Fuchs T, Jenal U: Regulation of D-xylose metabolism in Caulobacter crescentus by a Lacl-type repressor. J Bacteriol 2007, 189(24):8828-8834.

17. Curtis PD, Brun YV: Getting in the loop: regulation of development in Caulobacter crescentus. Microbiol Mol Biol Rev 2010, 74(1):13-41.

18. Barnett MJ, Fisher RF: Global gene expression in the rhizobial-legume symbiosis. Symbiosis 2006, 42(1):1-24.

19. Peterson TA, Russelle MP: Alfalfa and the nitrogen cycle in the Corn Belt. J Soil Water Conserv 1991, 46(3):229-235

20. Graham PH, Vance CP: Legumes: importance and constraints to greater use. Plant Physiol 2003, 131(3):872-877.

21. Khan SR, Gaines J, Roop RM 2nd, Farrand SK: Broad-host-range expression vectors with tightly regulated promoters and their use to examine the influence of TraR and TraM expression on Ti plasmid quorum sensing. Appl Environ Microbiol 2008, 74(16):5053-5062.

22. Pini F, Frage B, Ferri L, De Nisco NJ, Mohapatra SS, Taddei L, Fioravanti A, Dewitte F, Galardini M, Brilli M, Villeret V, Bazzicalupo M, Mengoni A, Walker GC, Becker A, Biondi EG: The DivJ, CbrA and PleC system controls DivK phosphorylation and symbiosis in Sinorhizobium meliloti. Mol Microbiol 2013, 90(1):54-71.

23. Poysti NJ, Loewen ED, Wang Z, Oresnik IJ: Sinorhizobium meliloti pSymB carries genes necessary for arabinose transport and catabolism. Microbiology 2007, 153(Pt 3):727-736.

24. Geddes BA, Oresnik IJ: Inability to catabolize galactose leads to increased ability to compete for nodule occupancy in Sinorhizobium meliloti. J Bacteriol 2012, 194(18):5044-5053.

25. Mauchline TH, Fowler JE, East AK, Sartor AL, Zaheer R, Hosie AH, Poole PS, Finan TM: Mapping the Sinorhizobium meliloti 1021 solute-binding protein-dependent transportome. Proc Natl Acad Sci USA 2006, 103(47):17933-17938.

26. Brüggemann C, Denger K, Cook AM, Ruff J: Enzymes and genes of taurine and isethionate dissimilation in Paracoccus denitrificans. Microbiology 2004, 150(Pt 4):805-816.

27. Wilson JJ, Kappler U: Sulfite oxidation in Sinorhizobium meliloti. Biochim Biophys Acta 2009, 1787(12):1516-1525.

28. Tett AJ, Rudder SJ, Bourdes A, Karunakaran R, Poole PS: Regulatable vectors for environmental gene expression in Alphaproteobacteria. Appl Environ Microbiol 2012, 78(19):7137-7140.

29. Harrison CL, Crook MB, Peco G, Long SR, Griffitts JS: Employing site-specific recombination for conditional genetic analysis in Sinorhizobium meliloti. Appl Environ Microbiol 2011, 77(12):3916-3922.

30. Arango Pinedo C, Gage DJ: Plasmids that insert into the rhamnose utilization locus, rha: a versatile tool for genetic studies in Sinorhizobium meliloti. J Mol Microbiol Biotechnol 2009, 17(4):201-210.

31. Bringhurst RM, Gage DJ: An AraC-like transcriptional activator is required for induction of genes needed for alpha-galactoside utilization in Sinorhizobium meliloti. FEMS Microbiol Lett 2000, 188(1):23-27.

32. Gage DJ, Long SR: a-Galactoside uptake in Rhizobium meliloti: isolation and characterization of agpA, a gene encoding a periplasmic binding 
protein required for melibiose and raffinose utilization. J Bacterio/ 1998, 180(21):5739-5748.

33. Schlüter JP, Reinkensmeier J, Barnett MJ, Lang C, Krol E, Giegerich R, Long SR, Becker A: Global mapping of transcription start sites and promoter motifs in the symbiotic alpha-proteobacterium Sinorhizobium meliloti 1021. BMC Genomics 2013, 14:156.

34. Bringhurst RM, Cardon ZG, Gage DJ: Galactosides in the rhizosphere: utilization by Sinorhizobium meliloti and development of a biosensor. Proc Natl Acad Sci USA 2001, 98(8):4540-4545.

35. Bringhurst RM, Gage DJ: Control of inducer accumulation plays a key role in succinate-mediated catabolite repression in Sinorhizobium meliloti. J Bacteriol 2002, 184(19):5385-5392.

36. Arango Pinedo C, Bringhurst RM, Gage DJ: Sinorhizobium meliloti mutants lacking phosphotransferase system enzyme HPr or EllA are altered in diverse processes, including carbon metabolism, cobalt requirements, and succinoglycan production. J Bacterio/ 2008, 190(8):2947-2956.

37. Garcia PP, Bringhurst RM, Arango Pinedo C, Gage DJ: Characterization of a two-component regulatory system that regulates succinate-mediated catabolite repression in Sinorhizobium meliloti. J Bacteriol 2010, 192(21):5725-5735.

38. Becker A, Barnett MJ, Capela D, Dondrup M, Kamp PB, Krol E, Linke B, Rüberg S, Runte K, Schroeder BK, Weidner S, Yurgel SN, Batut J, Long SR, Pühler A, Goesmann A: A portal for rhizobial genomes: RhizoGATE integrates a Sinorhizobium meliloti genome annotation update with postgenome data. J Biotechnol 2009, 140(1-2):45-50.

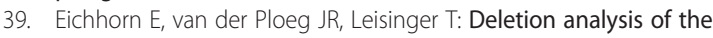
Escherichia coli taurine and alkanesulfonate transport systems. J Bacteriol 2000, 182(10):2687-2695.

40. van der Ploeg JR, Weiss MA, Saller E, Nashimoto H, Saito N, Kertesz MA, Leisinger T: Identification of sulfate starvation-regulated genes in Escherichia coli: a gene cluster involved in the utilization of taurine as a sulfur source. J Bacteriol 1996, 178(18):5438-5446.

41. Masepohl B, Fuhrer F, Klipp W: Genetic analysis of a Rhodobacter capsulatus gene region involved in utilization of taurine as a sulfur source. FEMS Microbiol Lett 2001, 205(1):105-111.

42. Johnson M, Zaretskaya I, Raytselis Y, Merezhuk Y, McGinnis S, Madden TL: NCBI BLAST: a better web interface. Nucleic Acids Res 2008 36(Web Server issue):W5-W9.

43. Wiethaus J, Schubert B, Pfander Y, Narberhaus F, Masepohl B: The GntR-like regulator TauR activates expression of taurine utilization genes in Rhodobacter capsulatus. J Bacteriol 2008, 190(2):487-493.

44. Seo JS, Chong H, Park HS, Yoon KO, Jung C, Kim JJ, Hong JH, Kim H, Kim JH, Kil JI, Park CJ, Oh HM, Lee JS, Jin SJ, Um HW, Lee HJ, Oh SJ, Kim JY, Kang $H L$, Lee SY, Lee KJ, Kang HS: The genome sequence of the ethanologenic bacterium Zymomonas mobilis ZM4. Nat Biotechnol 2005, 23(1):63-68.

45. Fields AT, Navarrete CS, Zare AZ, Huang Z, Mostafavi M, Lewis JC, Rezaeihaghighi Y, Brezler BJ, Ray S, Rizzacasa AL, Barnett MJ, Long SR, Chen EJ, Chen JC: The conserved polarity factor podJ1 impacts multiple cell envelope-associated functions in Sinorhizobium meliloti. Mol Microbiol 2012, 84(5):892-920.

46. Pickering $B S$, Oresnik IJ: The twin arginine transport system appears to be essential for viability in Sinorhizobium meliloti. J Bacteriol 2010 192(19):5173-5180.

47. Bastiat B, Sauviac L, Picheraux C, Rossignol M, Bruand C: Sinorhizobium meliloti sigma factors RpoE1 and RpoE4 are activated in stationary phase in response to sulfite. PLOS One 2012, 7(11):e50768.

48. Miller JH: Experiments in Molecular Genetics. Cold Spring Harbor, NY: Cold Spring Harbor Laboratory; 1972

49. Poindexter JS: Biological properties and classification of the Caulobacter group. Bacterio/ Rev 1964, 28:231-295.

50. Ely B: Genetics of Caulobacter crescentus. Methods Enzymol 1991, 204:372-384.

51. Ausubel FM, Brent R, Kingston RE, Moore DD, Seidman JG, Smith JA, Struhl K: Current Protocols in Molecular Biology. New York, NY: John Wiley \& Sons; 1998.

52. Goodman AE, Rogers PL, Skotnicki ML: Minimal medium for isolation of auxotrophic Zymomonas mutants. Appl Environ Microbiol 1982, 44(2):496-498

53. Finan TM, Kunkel B, De Vos GF, Signer ER: Second symbiotic megaplasmid in Rhizobium meliloti carrying exopolysaccharide and thiamine synthesis genes. J Bacteriol 1986, 167(1):66-72.

54. Evinger M, Agabian N: Envelope-associated nucleoid from Caulobacter crescentus stalked and swarmer cells. J Bacteriol 1977, 132(1):294-301.
55. Swings J, De Ley J: The biology of Zymomonas. Bacteriol Rev 1977, 41(1):1-46.

56. Meade HM, Long SR, Ruvkun GB, Brown SE, Ausubel FM: Physical and genetic characterization of symbiotic and auxotrophic mutants of Rhizobium meliloti induced by transposon Tn5 mutagenesis. J Bacteriol 1982, 149(1):114-122.

57. Kovach ME, Elzer PH, Hill DS, Robertson GT, Farris MA, Roop RM, Peterson KM: Four new derivatives of the broad-host-range cloning vector pBBR1MCS, carrying different antibiotic-resistance cassettes. Gene 1995, 166(1):175-176.

58. Marx CJ, Lidstrom ME: Development of improved versatile broad-host-range vectors for use in methylotrophs and other Gram-negative bacteria. Microbiology 2001, 147(Pt 8):2065-2075.

59. Quandt J, Hynes MF: Versatile suicide vectors which allow direct selection for gene replacement in gram-negative bacteria. Gene 1993, 127(1):15-21.

60. Oke V, Long SR: Bacterial genes induced within the nodule during the Rhizobium-legume symbiosis. Mol Microbiol 1999, 32(4):837-849.

61. Griffitts JS, Long SR: A symbiotic mutant of Sinorhizobium meliloti reveals a novel genetic pathway involving succinoglycan biosynthetic functions. Mol Microbiol 2008, 67(6):1292-1306.

62. Sambrook J, Fritsch EF, Maniatis T: Molecular Cloning: A Laboratory Manual. 2nd edition. Cold Spring Harbor, N.Y: Cold Spring Harbor Laboratory Press; 1989.

63. Beck S, Marlow VL, Woodall K, Doerrler WT, James EK, Ferguson GP: The Sinorhizobium meliloti MsbA2 protein is essential for the legume symbiosis. Microbiology 2008, 154(Pt 4):1258-1270.

doi:10.1186/s12866-014-0295-2

Cite this article as: Mostafavi et al:: Analysis of a taurine-dependent promoter in Sinorhizobium meliloti that offers tight modulation of gene expression. BMC Microbiology 2014 14:295.

\section{Submit your next manuscript to BioMed Central and take full advantage of:}

- Convenient online submission

- Thorough peer review

- No space constraints or color figure charges

- Immediate publication on acceptance

- Inclusion in PubMed, CAS, Scopus and Google Scholar

- Research which is freely available for redistribution

Submit your manuscript at www.biomedcentral.com/submit
C Biomed Central 